\title{
Does Checklist Implementation Improve Quantity of Data Transfer: An Observation in Postanesthesia Care Unit (PACU)
}

\author{
Lauren S. Park ${ }^{1,2}$, Gloria Yang2, Kay See Tan ${ }^{3}$, Charlotte H. Wong, ${ }^{3,4}$, Sabine Oskar2, \\ Ruth A. Borchardt², Luis E. Tollinche ${ }^{2 *}$ \\ ${ }^{1}$ The Warren Alpert Medical School of Brown University, Providence, RI, USA \\ ${ }^{2}$ Department of Anesthesiology and Critical Care Medicine, Memorial Sloan Kettering Cancer Center, New York City, NY, USA \\ ${ }^{3}$ Department of Epidemiology and Biostatistics, Memorial Sloan Kettering Cancer Center, New York City, NY, USA \\ ${ }^{4}$ Cornell University, Ithaca, NY, USA \\ Email: *tollincl@mskcc.org
}

How to cite this paper: Park, L.S., Yang, G., Tan, K.S., Wong, C.H., Oskar, S., Borchardt, R.A. and Tollinche, L.E. (2017) Does Checklist Implementation Improve Quantity of Data Transfer: An Observation in Postanesthesia Care Unit (PACU). Open Journal of Anesthesiology, 7, 69-82. https://doi.org/10.4236/ojanes.2017.74007

Received: March 14, 2017

Accepted: April 24, 2017

Published: April 28, 2017

Copyright (c) 2017 by authors and Scientific Research Publishing Inc. This work is licensed under the Creative Commons Attribution International License (CC BY 4.0).

http://creativecommons.org/licenses/by/4.0/

\begin{abstract}
Background: Omission of patient information in perioperative communication is closely linked to adverse events. Use of checklists to standardize the handoff in the post anesthesia care unit (PACU) has been shown to effectively reduce medical errors. Objective: Our study investigates the use of a checklist to improve quantity of data transfer during handoffs in the PACU. Design: A cross-sectional observational study. Setting: PACU at Memorial Sloan Kettering Cancer Center (MSKCC); June 13, 2016 through July 15, 2016. Patients, other participants: We observed the handoff reports between the nurses, PACU midlevel providers, anesthesia staff, and surgical staff. Intervention: A physical checklist was provided to all anesthesia staff and recommended to adhere to the list at all observed PACU handoffs. Main outcome measure: Quantity of reported handoff items during 60 pre- and 60 post-implementation of a checklist. Results: Composite value from both surgical and anesthesia reports showed an increase in the mean report of 8.7 items from pre-implementation period to 10.9 post-implementation. Given that surgical staff reported the mean of 5.9 items pre-implementation and 5.5 items postimplementation without intervention, improvements in anesthesia staff report with intervention improved the overall handoff data transfer. Conclusions: Using a physical 12-item checklist for PACU handoff increased overall data transfer.
\end{abstract}

\section{Keywords}

Checklist, PACU, Recovery Room, Data Transfer, Handoff 


\section{Introduction}

\subsection{Communication to Improve Patient Safety}

Miscommunication is a major patient safety concern. In 2016, The Joint Commission reported communication error as the number one cause of all anesthesia related sentinel events for the period 2004 to 2015 [1]. In the analysis of 444 surgical malpractice claims, 60 cases involved communication breakdown. When multiple healthcare providers across departments and disciplines care for a patient, mistakes in transmitting increasingly complex patient information have been shown to lead to patient harm [2] [3]. Handoff is a transfer of information and professional responsibilities across teams [4]. Despite the wide use of an electronic health record (EHR), a verbal synchronous, face-to-face communication in real-time is a fundamental paradigm of clinical discussion that provides a critical structure and an opportunity for an interactive discussion about a patient [5] [6] [7]. For that reason, The American Society of Anesthesiologist's standard of care requires the presence of intraoperative anesthesia staff for monitoring during transport and verbal report [8].

From review of surgical malpractice claims, the highest percentage of perioperative mistakes, including $43 \%$ of all communication failures, occurs postoperatively as a result of poor handoffs [9]. Studies have shown that poor handoffs increase the risk of patient harm [2] [3] [9] [10] [11] [12] and that standardizing communication protocols for handoffs can decrease medical errors and adverse events [13] [14] [15] [16]. Lack of standard guidelines produces inconsistent reports that are vulnerable to omission of pertinent information. Our objective was to quantify the amount of information transferred. The omission of data has been associated with worse outcomes than passing on poor quality of information [17]. A complete omission of information occurred in $57 \%$ of surgical malpractice claims [9]. Observation of handoffs showed items deemed vital components of handoff were reported less than half of the times [18].

Inadequate communication in PACU has been shown to increase morbidity and mortality [19]; a review of 419 reports from Anesthetic Incident Monitoring Study (AIMS) indicated a failure of communication as the second most common contributing factor that led to adverse events in recovery units [10]. PACU is especially vulnerable to communication failures between providers because of physical transfer of patient, collaboration of multiple clinicians, and similar patient histories are common features of PACU [17] [20].

\subsection{Why a Checklist?}

To avoid adverse events caused by miscommunication, The Joint Commission mandated "a standardized approach to handoffs" as a patient safety goal in 2006 [21]. Checklists have been used to standardize consistency in communication among providers and to reduce morbidity and mortality in surgical settings [22]. Checklists in PACU to standardize handoff communications have also been studied to show improvement in data transfer [23] [24] [25] [26] and reduction in 
medical errors [13] [15] [27]. Multicenter handoff interventions using a handoff checklist in PACU showed decrease in preventable adverse events across disciplines and departments [15] [27]. In addition, use of checklists has shown improvements in nursing staff satisfaction and handoff efficiency [25].

Overall, a checklist accomplishes two goals for both intraoperative and postoperative care providers. First, it provides a guideline that defines a standard for a handoff. Second, a physical checklist is used as a reminder of items to prevent omission of information [18] [26].

\subsection{Goal \& Hypothesis}

The goal is to establish measures to decrease perioperative miscommunication and improve patient safety through standardized PACU handoff protocol. We hypothesize that a physical checklist will increase data transfer and efficiency at our PACU, and prevent omission of pertinent patient information in handoff.

\section{Methods}

\subsection{IRB Approval}

IRB exemption was approved by MSKCC under the criteria of observation of public behavior and collection of unidentifiable information of clinician interactions. IRB exemption was approved on May 16, 2016.

\subsection{Derivation of the Checklist}

According to a systemic review of 31 studies on PACU handoff, a handoff should include at minimum: patient information, anesthesia information, surgical information, current status, and care plan [17]. A published "Anesthesia Handover Checklist" by Lin and colleagues was used as the initial structural framework. The initial checklist included: Patient, Underlying diagnosis/procedure, Technique-anesthetic, Status of procedure, Past significant medical history, Allergies, Timing/expected duration, Immediate expected events next 30 min, Emergence plan, Noteworthy aspects of case, Treatment plan for post op care, Fluids/EBL, Induction events, Records available for review, Signs-vitals, and Transfer care to. These items listed out a mnemonic: PUTS PATIENT FIRST [28]. This checklist included key elements of the transfer of care measures recommended by The American Society of Anesthesiologists [29]. Following the recommendations from various studies that emphasized flexibility in making adjustments according to the implemented institutions [15] [24] [30], the pilot week was used to adjust the working checklist according to the practices at our institution (Figure 1(a)). Multiple iterations were made to test usability and strength of the checklist.

Every item was deemed equally important, and given a score of 1 . Although surgical and anesthesia staff received separate grades, the primary endpoint was the total number of checklist items addressed by either department during the PACU handoff. This value ranged from the minimum of 0 to the maximum of 12. For the composite score, if an item is addressed by either a surgical or anes- 


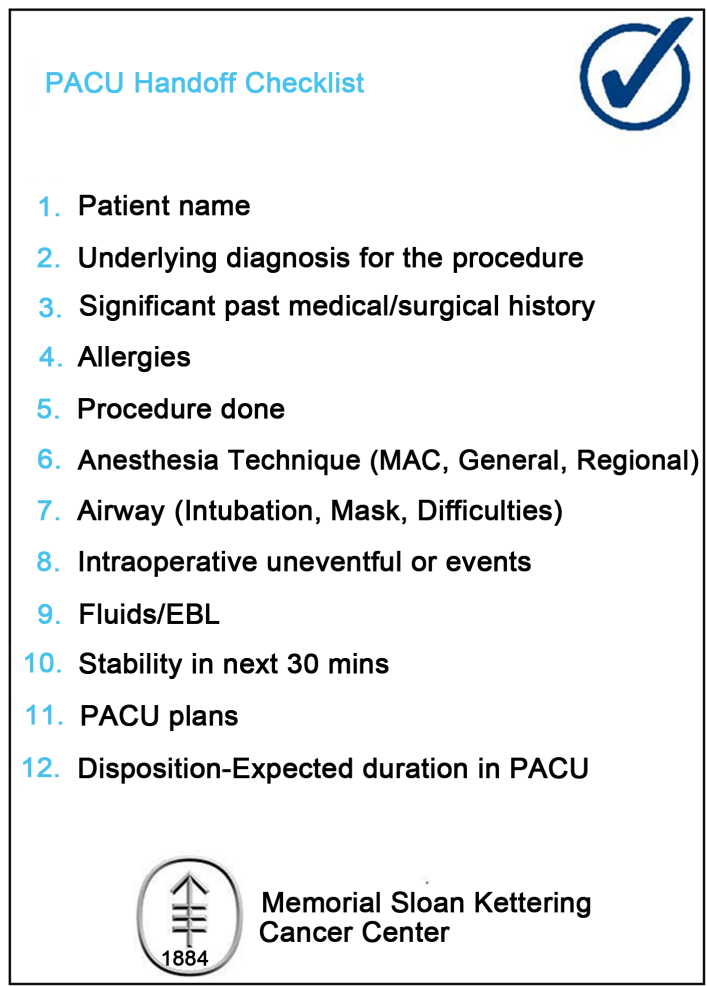

(a)

\begin{tabular}{|c|c|}
\hline PACU Checklist & (1) \\
\hline 1. Patient Name & $\begin{array}{l}\text { 7. Airway (Intubation, Mask, } \\
\text { Difficulties) }\end{array}$ \\
\hline $\begin{array}{l}\text { 2. Underlying diagnosis for } \\
\text { the procedure }\end{array}$ & $\begin{array}{l}\text { 8. Intraoperative uneventful } \\
\text { or events }\end{array}$ \\
\hline $\begin{array}{l}\text { 3. Significant past } \\
\text { medical/surgical history }\end{array}$ & 9. Fluids/EBL \\
\hline 4. Allergies & 10. stability in next 30 mins \\
\hline 5. Procedure done & 11. PACU plans \\
\hline $\begin{array}{l}\text { 6. Anesthesia Technique } \\
\text { (MAC, General, Regional) }\end{array}$ & 12. Disposition \\
\hline
\end{tabular}

(b)

Figure 1. (a) Full-sized checklist that was displayed by every PACU bed; (b) ID badgesized checklist for post-implementation period.

thesia staff, the item is considered to be addressed, and a score of 1 is allocated to the item. For department based scores, the surgical and anesthesia staff reports received separate score of 1 per item accordingly. The start and end time of the handoff was recorded for assessing the duration of handoff rounded to a whole minute. Lastly, every handoff was assigned an unidentifiable number to match the data between two observers.

Total duration of the study included 5 weeks of observation in the main PACU. The first week preceded the study to make adjustments to the checklist as a pilot period. All handovers were observed in real time by two observers. 
This pilot study yielded $100 \%$ consensus on "item qualified" between attending anesthesiologists and the observers. The observers were physically present at all observed handoffs between June 13, 2016 and July 15, 2016 from 10AM to 5PM. Immediately after each handoff, two observers resolved any differences in assessment and arrived at $100 \%$ consensus.

\subsection{Pre-Implementation Period}

Second and third weeks served as the control period. Observers gathered data before the checklist was implemented to gauge the current quality of PACU handoff. Both anesthesia and surgical staff being observed were not informed of the reason for the presence of observers in PACU to avoid isolated improvements in handoff behavior.

\subsection{Post-Implementation Period}

After pre-implementation period and prior to the official implementation of the checklist, all anesthesia staff-including attending anesthesiologist, Certified Registered Nurse Anesthetists (CRNAs), resident physicians, and CRNA studentswere made aware of the study. They were provided an electronic and physical copy of the checklist. An A4-sized laminated checklist was available by every patient bed. Additionally, ID badge-sized checklists were distributed to every provider (Figure 1(b)). During the last two weeks of the study, anesthesia staff were asked to use the checklist by the observers before each report. Surgical staff were not part of the intervention although data were collected from their reports.

\subsection{Statistical Analysis}

A traditional randomized study would randomize each handoff 1:1 to the group with or without a checklist. However, this approach would require some staff to unlearn the checklist hints after being exposed to it. Because of these logistical and feasibility issues, our study is based on convenience sampling in that the first two weeks of the study was pre-implementation of the checklist, while the second two weeks was post-implementation. This approach assumes that the case mix (patient and surgical characteristics) is similar between the two phases of the study, which is reasonable in this high volume cancer center. Power calculation was performed prior to the study to determine the minimal detectable difference (MDD) necessary to achieve $80 \%$ and $90 \%$ power for a two-sided t-test, given 50 patients in each arm and type I error rate of 0.05 . The MDD refers to the smallest treatment effect that can be identified assuming a known sample size. We assume mean of 5 items completed in the pre-implementation phase, with a conservative standard deviation (SD) of 5. The MDD are 2.85 and 3.25 for $80 \%$ and $90 \%$ power. This translates to an assumed mean of 7.85 and 8.25 checklist items completed in the post-implementation phase. If instead SD is 2 , the MDD changes to 1.14 and 1.30 for $80 \%$ and $90 \%$ power.

We examined each item individually to identify the proportion of handoffs addressed for the specific item between the two groups using Fisher's exact test. 
The secondary outcome of duration of PACU handoff is compared between the two groups using Wilcoxon rank sum test. As exploratory analyses, we compare the total number of items addressed in the post-implementation phase by consistency status to assess whether consistency impacts the quality of handoff. All analyses were repeated with the component scores which included the items addressed by the anesthesia provider only. All statistical tests were two-sided at alpha level of 0.05, performed using Stata 13 (Stata Corp, College Station, TX).

\section{Results}

\subsection{Data Transfer}

We observed a total of 120 PACU handoffs. 60 handoffs were each observed preimplementation and post-implementation of the checklist. Composite values analyzed items as addressed by either surgical or anesthesia staff. Department based values analyzed items addressed by surgical and anesthesia staff separately. Pre-implementation of a checklist, the composite value showed a mean of 8.7 $(\mathrm{SD}=1.5)$ items reported out of a total of 12 items on the checklist, and postimplementation the median report increased to 10.9 items (Table 1) (Figure 2). When anesthesia staff reports were analyzed independently, the mean reported items increased from $4.8(\mathrm{SD}=1.6)$ to $8.9(\mathrm{SD}=2.0)$ items post-implementation of the checklist (Table 1). Interestingly, surgical staff report stayed relatively consistent at mean of 5.9 items pre and 5.5 items post-implementation periods. In the analysis of anesthesia staff reports, items that were consistently reported at low numbers despite the checklist were: PACU Plans, Disposition-Expected Duration in PACU, Underlying Diagnosis, and Procedure Done (Table 2).

From the composite values, most improvements were seen with the following items: Allergies, Anesthesia Technique, and Airway (Table 2). In pre-implemen-

Table 1. Summary of median and $25^{\text {th }}, 75^{\text {th }}$ percentiles of reported items ${ }^{\text {a }}$.

\begin{tabular}{|c|c|c|c|c|c|c|c|c|c|}
\hline & \multicolumn{3}{|c|}{ Composite Value } & \multicolumn{3}{|c|}{ Anesthesia Reports Only } & \multicolumn{3}{|c|}{ Surgery Reports Only } \\
\hline & $\operatorname{Pre}^{b}$ & Post & P Value & Pre & Post & P Value & Pre & Post & $P$ Value \\
\hline Mean (SD) & $8.7(1.5)$ & $10.9(1.1)$ & $<0.0001$ & $4.8(1.6)$ & $8.9(2.0)$ & $<0.0001$ & $5.9(1.6)$ & $5.5(1.7)$ & 0.2 \\
\hline $25^{\text {th }}, 75^{\text {th }}$ percentiles & $8.0,10.0$ & $10.0,12.0$ & & $4.0,6.0$ & $7.5,10.0$ & & $5.0,7.0$ & $4.0,7.0$ & \\
\hline Median & 9.0 & 11.0 & $<0.0001$ & 5.0 & 9.0 & $<0.0001$ & 6.0 & 6.0 & 0.4 \\
\hline$<12$ items & $59(98 \%)$ & $39(65 \%)$ & $<0.0001$ & $60(100 \%)$ & $51(85 \%)$ & 0.003 & $60(100 \%)$ & $60(100 \%)$ & NA \\
\hline 12 items & $1(1.7 \%)$ & $21(35 \%)$ & & $0(0 \%)$ & $9(15 \%)$ & & & & \\
\hline$<11$ items & $53(88 \%)$ & $20(33 \%)$ & $<0.0001$ & $60(100 \%)$ & $47(78 \%)$ & 0.0001 & $60(100 \%)$ & $60(100 \%)$ & NA \\
\hline 11 items or $<$ & $7(12 \%)$ & $40(67 \%)$ & & $0(0 \%)$ & $13(22 \%)$ & & & & \\
\hline$<10$ items & $43(72 \%)$ & $6(10 \%)$ & $<0.0001$ & $59(98 \%)$ & $38(63 \%)$ & $<0.0001$ & $60(100 \%)$ & $60(100 \%)$ & NA \\
\hline 10 items or $<$ & $17(28 \%)$ & $54(90 \%)$ & & $1(1.7 \%)$ & $22(37 \%)$ & & & & \\
\hline
\end{tabular}

The reported items of composite value increased from a mean of 8.7 items to 10.9 items post-implementation of the checklist. Minimum number of reported items increased in the composite value and anesthesia reports post-implementation of the checklist. Pre: pre-implementation; Post: post-implementation. ${ }^{\text {a }}$ $=12$ items; ${ }^{b} \mathrm{~N}=60$ handoffs in every pre and post categories. 
Table 2. Breakdown of handoffs by reported items.

\begin{tabular}{|c|c|c|c|c|c|c|c|c|c|}
\hline \multirow[b]{2}{*}{ Items } & \multicolumn{3}{|c|}{ Composite Value } & \multicolumn{3}{|c|}{ Anesthesia Reports Only } & \multicolumn{3}{|c|}{ Surgery Reports Only } \\
\hline & Pre & Post & $P$ Value & Pre & Post & $P$ Value & Pre & Post & $P$ Value \\
\hline 1. Patient Name & $33(55 \%)$ & $53(88 \%)$ & $<0.0001$ & $14(23 \%)$ & $51(85 \%)$ & $<0.0001$ & $29(48 \%)$ & $23(38 \%)$ & 0.4 \\
\hline 2. Underlying diagnosis for the procedure & $53(88 \%)$ & $56(93 \%)$ & 0.5 & $14(23 \%)$ & $35(58 \%)$ & 0.0002 & $51(85 \%)$ & $47(78 \%)$ & 0.5 \\
\hline 3. Significant past medical/surgical history & $51(85 \%)$ & $59(98 \%)$ & 0.017 & $41(68 \%)$ & $55(92 \%)$ & 0.002 & $38(63 \%)$ & $34(57 \%)$ & 0.6 \\
\hline 4. Allergies & $38(63 \%)$ & $56(93 \%)$ & 0.0001 & $38(63 \%)$ & $56(93 \%)$ & 0.0001 & $2(3.3 \%)$ & $6(10 \%)$ & 0.3 \\
\hline 5. Procedure done & $60(100 \%)$ & $59(98 \%)$ & 1 & $11(18 \%)$ & $42(70 \%)$ & $<0.0001$ & $60(100 \%)$ & $57(95 \%)$ & 0.2 \\
\hline 6. Anesthesia technique & $35(58 \%)$ & $56(93 \%)$ & $<0.0001$ & $34(57 \%)$ & $56(93 \%)$ & $<0.0001$ & $8(13 \%)$ & $2(3.3 \%)$ & 0.095 \\
\hline 7. Airway & $34(57 \%)$ & $56(93 \%)$ & $<0.0001$ & $33(55 \%)$ & $56(93 \%)$ & $<0.0001$ & $1(1.7 \%)$ & $0(0 \%)$ & 1 \\
\hline 8. Intraoperative uneventful or events & $44(73 \%)$ & $54(90 \%)$ & 0.032 & $30(50 \%)$ & $49(82 \%)$ & 0.0005 & $31(52 \%)$ & $34(57 \%)$ & 0.7 \\
\hline 9. Fluids/EBL & $59(98 \%)$ & $60(100 \%)$ & 1 & $59(98 \%)$ & $60(100 \%)$ & 1 & $22(37 \%)$ & $20(33 \%)$ & 0.8 \\
\hline 10. Stability in next 30 mins & $12(20 \%)$ & $41(68 \%)$ & $<0.0001$ & $5(8.3 \%)$ & $36(60 \%)$ & $<0.0001$ & $9(15 \%)$ & $6(10 \%)$ & 0.6 \\
\hline 11. PACU plans & $54(90 \%)$ & $57(95 \%)$ & 0.5 & $10(17 \%)$ & $17(28 \%)$ & 0.2 & $53(88 \%)$ & $56(93 \%)$ & 0.5 \\
\hline 12. Disposition-Expected duration in PACU & $48(80 \%)$ & $46(77 \%)$ & 0.8 & $1(1.7 \%)$ & $18(30 \%)$ & $<0.0001$ & $48(80 \%)$ & $44(73 \%)$ & 0.5 \\
\hline
\end{tabular}

Most improved reported items in composite value were items related to anesthesia, such as: patient name, allergies, anesthesia technique, and airway. Pre: pre-implementation; Post: post-implementation.

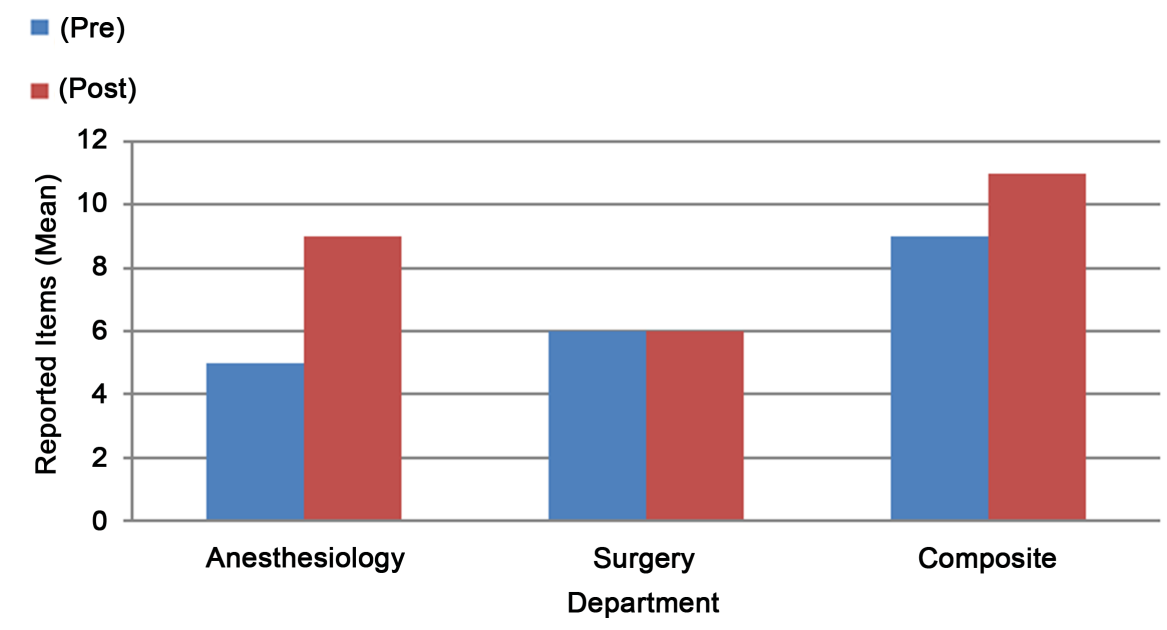

Figure 2. Post-implementation of the checklist, median reported items increased from nine to eleven in composite values. Abbreviation: Pre: pre-implementation; Post: postimplementation.

tation composite values, Allergies, Anesthesia Technique, and Airway were reported during $63 \%(38, \mathrm{~N}=60), 58 \%(35, \mathrm{~N}=60)$, and $57 \%(34, \mathrm{~N}=60)$ of the handoffs respectively. Post-implementation of a checklist, reports about Allergies, Anesthesia Technique, and Airway all increased to 93\% (56, $\mathrm{N}=60, p<$ $0.0001)$. In contrast, the least improvements in composite value were noted with Patient Name and Stability in 30 Minutes. Pre-implementation of a checklist, Patient Name and Stability in 30 Minutes were mentioned 55\% (33, N = 60) and $20 \%(12, \mathrm{~N}=60)$ of the handoffs, respectively. Post-implementation of a checklist, Patient Name and Stability in 30 Minutes increased to 88\% (53, N =60, $p<$ $0.0001)$ and $68 \%(41, \mathrm{~N}=60, p<0.0001)$ respectively (Table 2 ). 


\subsection{Secondary Analysis}

Duration of each handoff is the total time of both surgical and anesthesia staff reports rounded to a minute. Post-implementation, the median duration of handoff, is increased by one minute (Table 3). However, in comparison to the increase in the number of reported items with longer handoffs during the pre-implementation period, duration of the handoffs was independent of the number of reported items post-implementation (Table 4).

\section{Discussion}

Our results demonstrate that, in the setting studied, the use of a checklist improved the overall quantity of data transfer during PACU handoff. A checklist was introduced and implemented for two weeks. During the post-implementation period, more items were reported in all intervals of "handoff duration" in comparison to pre-implementation period. Using a checklist to prevent omission of patient information during handoff is important because miscommunication from multiple care transfer has been shown to increase patient harm [2] [3] [9] [10] [11] [12]. To mitigate these adverse events, a use of checklist in PACU has shown not only an increase in data transfer [23] [24] [25] [26] but also

Table 3. Summary of Handoff Duration (minute) ${ }^{\mathrm{a}}$.

\begin{tabular}{ccccccc}
\hline & N & Mean & SD & Median & Min & Max \\
\hline Pre & 60 & 2.9 & 1.3 & 3 & 1 & 7 \\
Post & 60 & 3.9 & 1.8 & 4 & 1 & 9 \\
\hline
\end{tabular}

Overall duration of a handoff increased during the post-implementation period of the checklist. Pre: pre-implementation; Post: post-implementation; SD: standard deviation; Min: minimum; Max: maximum. ${ }^{a}$ Duration included both surgical and anesthesia reports.

Table 4. Breakdown of handoff duration ${ }^{\mathrm{a}, \mathrm{b}}$.

\begin{tabular}{|c|c|c|c|c|c|c|}
\hline \multirow[b]{2}{*}{ Duration } & \multicolumn{3}{|c|}{ Pre } & \multicolumn{3}{|c|}{ Post } \\
\hline & Median & $\begin{array}{c}25^{\text {th }}, 75^{\text {th }} \\
\text { percentile }\end{array}$ & Percentage & Median & $\begin{array}{c}25^{\text {th }}, 75^{\text {th }} \\
\text { percentile }\end{array}$ & Percentage \\
\hline $1 \mathrm{~min}$ & 6.5 & $6.0,9.0$ & $(\mathrm{~N}=8 ; 73 \%)$ & 11.0 & $10.0,12.0$ & $(\mathrm{~N}=3 ; 27 \%)$ \\
\hline $2 \min$ & 8.5 & $7.5,9.0$ & $(\mathrm{~N}=16 ; 62 \%)$ & 12.0 & $10.0,12.0$ & $(\mathrm{~N}=10 ; 38 \%)$ \\
\hline $3 \mathrm{~min}$ & 9.0 & $8.0,10.0$ & $(\mathrm{~N}=21 ; 58 \%)$ & 11.0 & $10.0,11.0$ & $(\mathrm{~N}=15 ; 42 \%)$ \\
\hline $4 \mathrm{~min}$ & 9.5 & $9.0,10.0$ & $(\mathrm{~N}=8 ; 36 \%)$ & 11.0 & $11.0,12.0$ & $(\mathrm{~N}=14 ; 64 \%)$ \\
\hline $5 \mathrm{~min}$ & 8.0 & $8.0,9.0$ & $(\mathrm{~N}=5 ; 45 \%)$ & 11.0 & $10.0,12.0$ & $(\mathrm{~N}=6 ; 55 \%)$ \\
\hline $6 \mathrm{~min}$ & 10.0 & $10.0,10.0$ & $(\mathrm{~N}=1 ; 13 \%)$ & 11.0 & $10.0,12.0$ & $(\mathrm{~N}=7 ; 88 \%)$ \\
\hline $7 \mathrm{~min}$ & 11.0 & $11.0,11.0$ & $(\mathrm{~N}=1 ; 25 \%)$ & 11.0 & $10.0,11.0$ & $(\mathrm{~N}=3 ; 75 \%)$ \\
\hline $8 \mathrm{~min}$ & - & & & - & & \\
\hline $9 \mathrm{~min}$ & - & & & 11.5 & $11.0,12.0$ & $(\mathrm{~N}=2 ; 100 \%)$ \\
\hline
\end{tabular}

Improvements in handoff during the post-implementation period were independent of the duration. Pre:

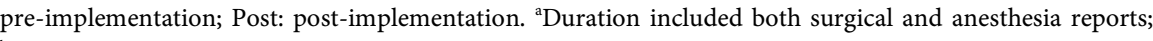
${ }^{\mathrm{b}} \mathrm{N}=12$. 
a decrease in medical errors [13] [14] [15]. Our study adds that a checklist reminds the staff of defined standard of items to report in order to minimize information omission during PACU handoff. Furthermore, the quantity of minimum data transferred during handoff is independent of the quality of the reports, which is more closely associated with complexity of patient history and not an objective of this study.

\subsection{Quantity of Data Transfer}

There are two important reasons for analyzing the data as composite values and department based values. First, PACU handoff is provided by both the surgical and anesthesia team at our institution. The median number of items reported by surgical staff stayed the same at a median of 6 items out of the total 12 during post-implementation period. This data indicates that the increase in overall improvement in handoff during post-implementation can be attributed to improvements in anesthesia reports without unintended observational influence on the quality of surgical staff reports. Quality of anesthesia reports as a standalone report is also important because collaborative report may not be a standard of practice at all institutions. In many institutions, only anesthesia gives report during PACU handoff. As an ideal standard, anesthesia staff should be able to adequately report surgical information in case anesthesia staff is the only informant of intraoperative events.

Second, comparing composite and department based values helped us to identify items pertinent to either surgical or anesthesia staff during handoffs. Items related to surgical procedure improved the least in the anesthesia staff reports (i.e. PACU plans, Disposition-Expected Duration in PACU, Underlying diagnosis, and Procedure done) (Figure 3). Because compliance of reporting surgical information by anesthesia staff was lowest in a similar study, the data was used to recommend presence of surgical staff during handoffs [31]. Items relevant to the practice of anesthesia improved the most in anesthesia reports and composite value (i.e. Allergies, Anesthesia Technique, and Airway) (Figure 4). Considering that prior to implementation of a checklist, about half of the reports did not include these anesthesia specific information, a checklist reduced omission of at least the most relevant information.

\subsection{Duration}

Contradictory to our hypothesis that a checklist would reduce the duration of a handoff, we observed an overall increase in median time spent during a handoff. Previous studies have shown conflicting reports on the effect of handoff duration after implementing a checklist [23] [25] [26] [31].

The lack of training in using the checklist led to providers stumbling or pausing during the report. Majority of the informal feedback from the anesthesia staff were disturbances to their original "flow" with a different order of items and some unfamiliar items on the checklist. Despite the foreseen improvements in handoff with a physical checklist [26], multimodal staff training models could 


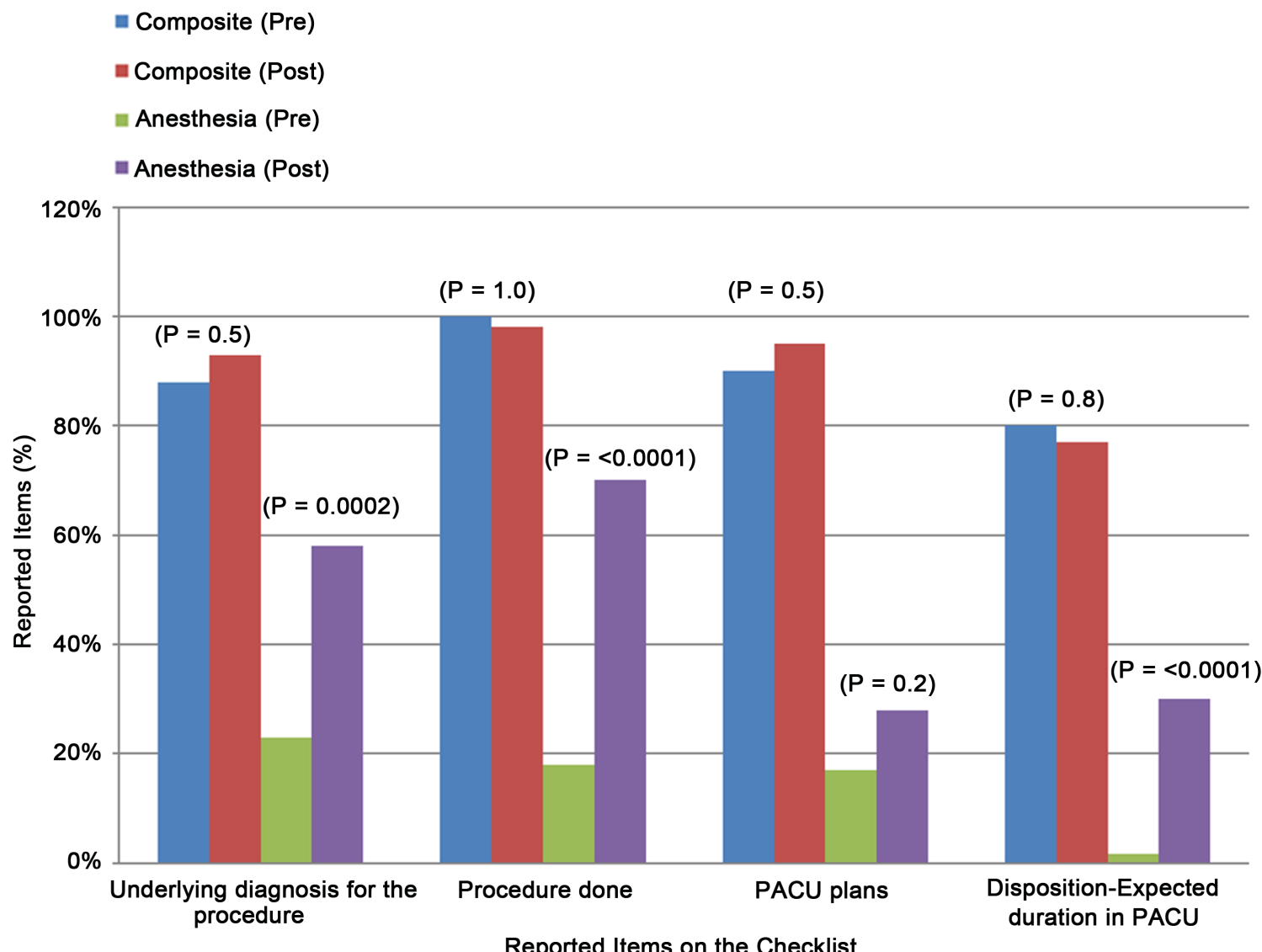

Figure 3. Analysis of the anesthesia reports showed least improvements with items related to surgical practice. Pre: pre-implementation; Post: post-implementation.

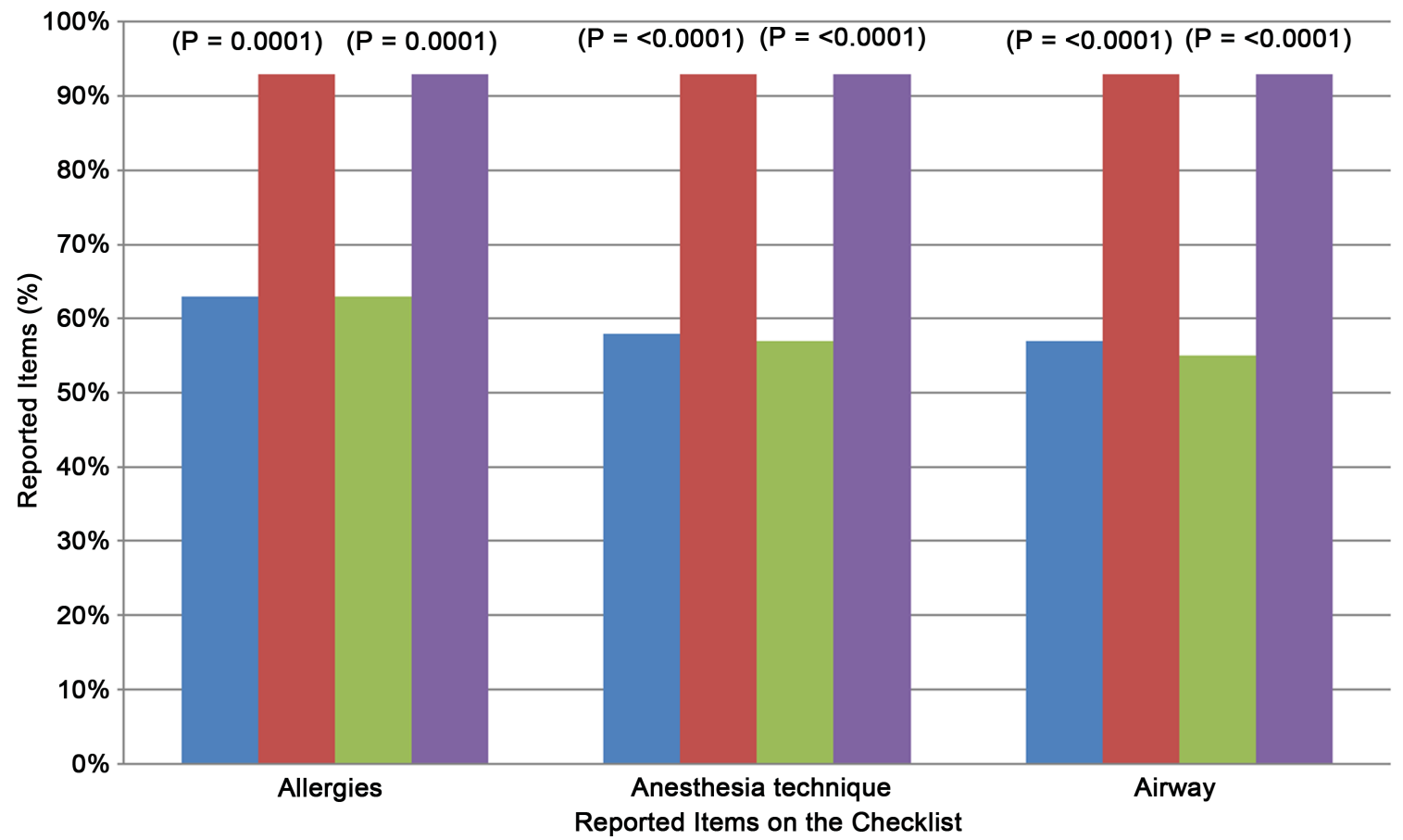

Figure 4. Analysis of the anesthesia reports showed most improvements with items related to anesthesia practice. Pre: pre-implementation; Post: post-implementation. 
improve incorporating a new checklist to practice [24] [25] [27] [32]. Second, we recommend multiple Plan-Do-Study-Act cycles 24 and incorporating staff feedback18 to design a checklist that better fits the context of each institution.

\subsection{Limitations}

Hawthorne effect is the influence of the presence of an observer on observed behavior. During pre-implementation phase, anesthesia staff was given limited details on what we were observing. We cannot overlook the influence of the presence of the two observers during all observed handoffs. It is likely that data transfer improved for our control group simply because of Hawthorne effect. For instance, we can assume that the observed handoffs were more comprehensive than the baseline handoffs before our study. It follows then, that the actual improvement in handoff is indeed better than we reported. We expect to find more pronounced improvement if our results were subject to the Hawthorne effect.

Although prior studies have correlated adverse events with poor handoff [2] [3], direct comparison to patient outcome with a handoff checklist in a randomized trial is ideal but difficult to accomplish.33 Thus, deriving from previous studies, we assume that our improvement in data transfer will decrease adverse events and improve patient outcome. Secondly, although complexity of the patient history may take longer to report, patient population was not defined or restricted [33]. Patients may vary greatly in their phase of cancer treatment at our institution. Our data is based on the local context and exact results cannot be generalized for other institutions without further multicenter investigation [34]. Thirdly, creating definitive categories of medications or tools with the help of practicing anesthesiologists, observers were taught to convert qualitative data from observations to quantitative data during the pilot week. Despite the $100 \%$ consensus made between two observers after every handoff, we cannot neglect the human variables in information gathering.

\section{Conclusion}

In conclusion, implementation of a physical checklist for PACU handoff increased overall data transfer and prevented omission of patient information. Report duration did not have an impact on overall data transfer. For future directions, we recommend incorporating staff feedback into Plan-Do-Study-Act cycles for an improved checklist to ensure compliance and familiarize the staff with the use of a checklist through multimodal training modules.

\section{Acknowledgements}

1) The authors would like to thank the anesthesia staff at Memorial Sloan Kettering Cancer Center for complying with the intervention during the study period.

2) Research reported in this publication was supported by the National Cancer Institute of the National Institutes of Health under Award Number 
R25CA020449. The content is solely the responsibility of the authors and does not necessarily represent the official views of the National Institutes of Health.

3) This research was funded in part through the NIH/NCI Cancer Center Support Grant P30 CA00874.

4) Authors do not have conflicts of interest.

5) Preliminary data of this study was presented at the $14^{\text {th }}$ Annual American Medical Association Research Symposium on November 11, 2016.

\section{References}

[1] (2016) Root Causes by Event Type. In: Sentinel Event Data, The Joint Commission, 9.

[2] Saager, L., Hesler, B.D., You, J., et al. (2014) Intraoperative Transitions of Anesthesia Care and Postoperative Adverse Outcomes. Anesthesiology, 121, 695-706. https://doi.org/10.1097/ALN.0000000000000401

[3] Hyder, J.A., Bohman, J.K., Kor, D.J., et al. (2016) Anesthesia Care Transitions and Risk of Postoperative Complications. Anesthesia \& Analgesia, 122, 134-144. https://doi.org/10.1213/ANE.0000000000000692

[4] Jeffcott, S.A., Evans, S.M., Cameron, P.A., Chin, G.S.M. and Ibrahim, J.E. (2009) Improving Measurement in Clinical Handover. Quality and Safety in Health Care, 18, 272-276. https://doi.org/10.1136/qshc.2007.024570

[5] Coiera, E. and Tombs, V. (1998) Communication Behaviours in a Hospital Setting: An Observational Study. BMJ: British Medical Journal, 316, 673-676. https://doi.org/10.1136/bmj.316.7132.673

[6] Lane-Fall, M.B., Speck, R.M., Ibrahim, S.A., Shea, J.A., McCunn, M. and Bosk, C.L. (2014) Are Attendings Different? Intensivists Explain Their Handoff Ideals, Perceptions, and Practices. Annals of the American Thoracic Society, 11, 360-366. https://doi.org/10.1513/AnnalsATS.201306-151OC

[7] Flemming, D. and Hübner, U. (2013) How to Improve Change of Shift Handovers and Collaborative Grounding and What Role Does the Electronic Patient Record System Play? Results of a Systematic Literature Review. International Journal of Medical Informatics, 82, 580-592. https://doi.org/10.1016/j.ijmedinf.2013.03.004

[8] ASAHQ (2014) Anesthesiologists ASo. Standards for Postanesthesia Care. In: Standards and Practice Parameters.

http://www.asahq.org/quality-and-practice-management/standards-and-guidelines/

[9] Greenberg, C.C., Regenbogen, S.E., Studdert, D.M., et al. (2007) Patterns of Communication Breakdowns Resulting in Injury to Surgical Patients. Journal of the American College of Surgeons, 204, 533-540. https://doi.org/10.1016/j.jamcollsurg.2007.01.010

[10] Kluger, M.T. and Bullock, M.F.M. (2002) Recovery Room Incidents: A Review of 419 Reports from the Anaesthetic Incident Monitoring Study (AIMS). Anaesthesia, 57, 1060-1066. https://doi.org/10.1046/j.1365-2044.2002.02865.x

[11] Kitch, B.T., Cooper, J.B., Zapol, W.M., et al. (2008) Handoffs Causing Patient Harm: A Survey of Medical and Surgical House Staff. The Joint Commission Journal on Quality and Patient Safety, 34, 563-570. https://doi.org/10.1016/S1553-7250(08)34071-9

[12] Ong, M.-S. and Coiera, E. (2011) A Systematic Review of Failures in Handoff Communication during Intrahospital Transfers. The Joint Commission Journal on Quality and Patient Safety, 37, 274-284. 
https://doi.org/10.1016/S1553-7250(11)37035-3

[13] Catchpole, K.R., De Leval, M.R., McEwan, A., et al. (2007) Patient Handover from Surgery to Intensive Care: Using Formula 1 Pit-Stop and Aviation Models to Improve Safety and Quality. Pediatric Anesthesia, 17, 470-478.

https://doi.org/10.1111/j.1460-9592.2006.02239.x

[14] Starmer, A.J., Spector, N.D., Srivastava, R., et al. (2014) Changes in Medical Errors after Implementation of a Handoff Program. The New England Journal of Medicine, 371, 1803-1812. https://doi.org/10.1056/NEJMsa1405556

[15] Bigham, M.T., Logsdon, T.R., Manicone, P.E., et al. (2014) Decreasing HandoffRelated Care Failures in Children's Hospitals. Pediatrics, 134, e572-e579. https://doi.org/10.1542/peds.2013-1844

[16] Mueller, S.K., Yoon, C. and Schnipper, J.L. (2016) Association of a Web-Based Handoff Tool with Rates of Medical Errors. JAMA Internal Medicine, 176, 14001402. https://doi.org/10.1001/jamainternmed.2016.4258

[17] Segall, N., Bonifacio, A.S., Schroeder, R.A., Barbeito, A., et al. (2013) Can We Make Postoperative Patient Handovers Safer? A Systematic Review of the Literature. Survey of Anesthesiology, 57, 40-41. https://doi.org/10.1097/01.sa.0000425544.99583.4b

[18] Siddiqui, N., Arzola, C., Iqbal, M., et al. (2012) Deficits in Information Transfer between Anaesthesiologist and Postanaesthesia Care Unit Staff: An Analysis of Patient Handover. European Journal of Anaesthesiology, 29, 438-445. https://doi.org/10.1097/EJA.0b013e3283543e43

[19] Eichenberger, A.-S., Haller, G., Cheseaux, N., Lechappe, V., Garnerin, P. and Walder, B. (2011) A Clinical Pathway in a Post-Anaesthesia Care Unit to Reduce Length of Stay, Mortality and Unplanned Intensive Care Unit Admission. European Journal of Anaesthesiology, 28, 859-866.

[20] Smith, A.F., Pope, C., Goodwin, D. and Mort, M. (2008) Interprofessional Handover and Patient Safety in Anaesthesia: Observational Study of Handovers in the Recovery Room. British Journal of Anaesthesia, 101, 332-337. https://doi.org/10.1093/bja/aen168

[21] Joint Commission on Accreditation of Healthcare Organizations (2006) Joint Commission Announces 2006 National Patient Safety Goals. Nursing Economics, $24,76$.

[22] Haynes, A.B., Weiser, T.G., Berry, W.R., et al. (2009) A Surgical Safety Checklist to Reduce Morbidity and Mortality in a Global Population. The New England Journal of Medicine, 360, 491-499. https://doi.org/10.1056/NEJMsa0810119

[23] Potestio, C., Mottla, J., Kelley, E. and DeGroot, K. (2015) Improving Post Anesthesia Care Unit (PACU) Handoff by Implementing a Succinct Checklist. The Official Journal of the Anesthesia Patient Safety Foundation.

[24] Boat, A.C. and Spaeth, J.P. (2013) Handoff Checklists Improve the Reliability of Patient Handoffs in the Operating Room and Postanesthesia Care Unit. Pediatric Anesthesia, 23, 647-654. https://doi.org/10.1111/pan.12199

[25] Caruso, T.J., Marquez, J.L., Wu, D.S., Shaffer, J.A., et al. (2015) Implementation of a Standardized Postanesthesia Care Handoff Increases Information Transfer without Increasing Handoff Duration. The Joint Commission Journal on Quality and Patient Safety, 41, 35-42. https://doi.org/10.1016/S1553-7250(15)41005-0

[26] Salzwedel, C., Bartz, H.-J., Kühnelt, I., et al. (2013) The Effect of a Checklist on the Quality of Post-Anaesthesia Patient Handover: A Randomized Controlled Trial. International Journal for Quality in Health Care, 25, 176-181. https://doi.org/10.1093/intqhc/mzt009 
[27] Starmer, A.J., Spector, N.D., Srivastava, R., et al. (2014) Changes in Medical Errors after Implementation of a Handoff Program. The New England Journal of Medicine, 371, 1803-1812. https://doi.org/10.1056/NEJMsa1405556

[28] Lin, D.M., Chase, C.J. and Merkel, M.J. (2014) Anesthesia Handovers: Why Are They So Complicated? ASA Monitor, 78, 24-27.

[29] (2015) Anesthesiologists ASo. Post-Anesthetic Transfer of Care: Use of Checklist or Protocol for Direct Transfer of Care from Procedure Room to Intensive Care Unit (ICU). American Society of Anesthesiologists.

[30] Arora, V. and Johnson, J. (2006) A Model for Building a Standardized Hand-Off Protocol. The Joint Commission Journal on Quality and Patient Safety, 32, 646-655. https://doi.org/10.1016/S1553-7250(06)32084-3

[31] Karakaya, A., Moerman, A.T., Peperstraete, H., François, K., Wouters, P.F. and de Hert, S.G. (2013) Implementation of a Structured Information Transfer Checklist Improves Postoperative Data Transfer after Congenital Cardiac Surgery. European Journal of Anaesthesiology, 30, 764-769. https://doi.org/10.1097/EJA.0b013e328361d3bb

[32] Weinger, M.B., Slagle, J.M., Kuntz, A.H., et al. (2015) A Multimodal Intervention Improves Postanesthesia Care Unit Handovers. Anesthesia \& Analgesia, 121, 957971. https://doi.org/10.1213/ANE.0000000000000670

[33] Horwitz, L.I. (2013) Does Improving Handoffs Reduce Medical Error Rates? JAMA, 310, 2255-2256. https://doi.org/10.1001/jama.2013.281827

[34] Møller, T.P., Madsen, M.D., Fuhrmann, L. and Østergaard, D. (2013) Postoperative Handover: Characteristics and Considerations on Improvement: A Systematic Review. European Journal of Anaesthesiology, 30, 229-242. https://doi.org/10.1097/EJA.0b013e32835d8520

\section{Abbreviation List}

1) PACU: Post Anesthesia Care Unit

2) MSKCC: Memorial Sloan Kettering Cancer Center

3) EHR: Electronic Health Record

4) AIMS: Anesthetic Incident Monitoring Study

5) IRB: Institutional Review Board

6) CRNA: Certified Registered Nurse Anesthetist

7) MDD: Minimal Detectable Difference

8) SD: Standard Deviation 
Submit or recommend next manuscript to SCIRP and we will provide best service for you:

Accepting pre-submission inquiries through Email, Facebook, LinkedIn, Twitter, etc. A wide selection of journals (inclusive of 9 subjects, more than 200 journals) Providing 24-hour high-quality service

User-friendly online submission system

Fair and swift peer-review system

Efficient typesetting and proofreading procedure

Display of the result of downloads and visits, as well as the number of cited articles Maximum dissemination of your research work

Submit your manuscript at: http://papersubmission.scirp.org/

Or contact ojanes@scirp.org 